\title{
Selection for Reproductive Traits in White Egg Stock Using Independent Culling Levels
}

Author(s)
Schmidt GS1,2
Figueiredo EAP ${ }^{3}$
1 Animal Scientist, D.Sc., Embrapa Suínos e
Aves
2 Scholarship granted by CNPq
3 Animal Scientist, Ph.D., Embrapa Suínos

\section{Mail Address}

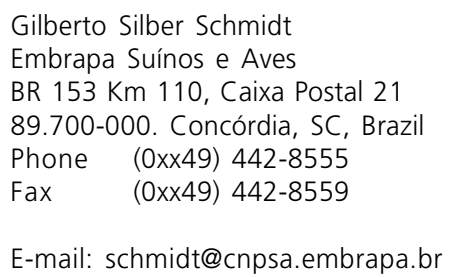

\section{Keywords}

Egg production, inbreeding, reproductive traits, selection culling levels.

\section{ABSTRACT}

The objective of this study was to report the response to selection for fertility and hatchability in white egg layers strains, based on sire and dam performance, and the effects of inbreeding on these traits. Two selected white egg strains (CC and DD) from Embrapa's poultry program under multiple trait selection were compared to a control strain (CCc). The control strain was established by randomly mating one male from each sire family to a non-related female from each dam family and was used to monitor genetic change in the selected lines. CC and DD were selected using family and individual information on hen-day egg production up to 40 weeks of age, egg weight, sexual maturity and 16-week-old body weight over five generations. Independent culling levels (ICL) were also used during population expansion to eliminate sires and dams with low fertility (FERT) and hatchability (HATC). Initially, FERT and HATC were over $90.0 \%$ in both selected and control strains. FERT and HATC of the selected and the control strains were compared during the last generation. FERT averages were 93.8, 93.8 and $94.4 \%$, and HATCH averages were 93.2, 91.6 and $93.1 \%$ for CC, DD and CCC respectively. FERT and $\mathrm{HATCH}$ means were not different among strains. Estimated inbreeding increased at a rate of $0.4 \%$ per generation in all strains. Selection using ICL was able to effectively maintain the high initial FERT and HATC levels, and provide potential for high selection intensity in other traits. Inbreeding depression was not observed for any trait, indicating that selection compensated for any negative effects of inbreeding.

\section{INTRODUCTION}

Poultry breeders must consider so many traits that are economically important that it becomes difficult to apply sufficient selection pressure on the Key traits in egg stocks are egg production rate, sexual maturity, viability, egg size, feed efficiency, fertility and hatchability. Others traits such as egg quality and body weight are generally of less importance, unless when a strain exhibits specific problems. Thus, with such a large number of traits, it is important to avoid placing more selection pressure on a trait than is required, so that selection intensity on the primary traits can be maintained.

The selection index theory assumes no major genes, additive gene action, and linear or quadratic economic weights. Indices work better when genes are at intermediate frequencies. Recessive genes with large negative effects and at very low frequency seriously violate index assumptions, and this appeared to be true of fertility and hatchability in the current studies. Also, heritability estimates are dependent on gene frequency. Thus, a gene with an intermediate frequency will make a larger contribution to heritability than it would at a low frequency. These 
factors indicate that indices may not be the most efficient method to maintain high levels of fertility and hatchability (Gowe et al., 1993).

Fertility and hatchability can be maintained in populations under multiple trait selection through culling of paternal and maternal families with low performance. This culling only of families with low fertility and hatchability allows the breeder to use higher selection intensity and to obtain greater genetic progress in primary traits such as egg production (Gowe \& Fairfull, 1985; Fairfull \& Gowe, 1990).

Inbreeding depression in small populations under selection reduces fertility and hatchability (Nordskog \& Hardiman. 1980; Ibe et al., 1983; Abplanalp, 1990). Where inbreeding is not so rapid, some evidence has shown that the depressive effect may be alleviated through selection (Gowe et al., 1993), but few reports exist on the effects of inbreeding on performance traits in laying hens (Kashyap et al. 1981; Gowe \& Fairfull, 1985; Ameli et al., 1991; Gowe et al., 1993).

The objective of this paper was to report the response to selection for fertility and hatchability, based on sire and dam performance, and the effects of inbreeding on these traits in white egg layer strains under multiple trait selection.

\section{MATERIAL AND METHODS}

Data from three white egg layer strains (CC, DD and (CC) of Brazilian National Swine and Poultry Research Center (Embrapa Suínos e Aves) were analyzed. CC and DD strains were incorporated to the breeding program after a Mycoplasma eradication program. The control strain (CCc) was established from CC strain, by randomly mating one male from each sire family to a non-related female from each dam family and was used to monitor genetic change in the selected lines.

The lines CC and DD were selected for egg production, egg weight, sexual maturity, 16-week-old body weight, fertility and hatchability over five generations. The selection criteria for egg production included the paternal half-sib and full-sib family averages and individual hen records on hen-day egg production rate up to 40 weeks. Individual egg weight means recorded at the $24^{\text {th }}, 32^{\text {nd }}, 36^{\text {th }}$ and $40^{\text {th }}$ weeks were used as selection criterion. A similar procedure was used to select for sexual maturity.

During expansion, up to 40 weeks, 8 females per male were artificially inseminated at 5 -days intervals. Eggs were stored until incubation for 10 days in a cold room $\left(17^{\circ} \mathrm{C}\right.$ and $90 \%$ relative humidity). In the selected strains, sires and dams were selected based on reproductive performance using incubation results. Progenies from sire and dam families with very low averages for fertility and hatchability were culled using independent levels so that progenies were eliminated. Approximately $10 \%$ of the male and female families were eliminated. The objective was to maintain the original high performance levels for these traits, with low expectation of genetic gain. Estimates of the genetic change in fertility and hatchability were obtained by regression of the deviation between the means of selected and control strains as a function of the generation number.

Inbreeding per generation $\left(F_{r}\right)$ was estimated through random mating using:

$$
F_{r}=1 / 8 S+1 / 8 D,
$$

where $S$ and $D$ are the numbers of sires and dams contributing to the next generation, respectively (Table 1). The restriction on pedigree information makes it impossible to calculate the full inbreeding coefficient. Therefore, $F_{r}$ will be underestimated.

\begin{tabular}{ccccccc}
\hline $\begin{array}{l}\text { Table 1 - Number of sires and dams contributing to the next } \\
\text { generation. } \\
\text { Generation }\end{array}$ & \multicolumn{2}{c}{ CC } & \multicolumn{2}{c}{ DD } & \multicolumn{2}{c}{ CCc } \\
\cline { 2 - 7 } & Sires & Dams & Sires & Dams & Sires & Dams \\
1 & 80 & 669 & 80 & 718 & 80 & 669 \\
2 & 42 & 240 & 49 & 267 & 70 & 184 \\
3 & 37 & 198 & 32 & 157 & 55 & 139 \\
5 & 24 & 139 & 24 & 143 & 22 & 133 \\
5 & 62 & 172 & 52 & 147 & 63 & 117 \\
\hline
\end{tabular}

In the last generation, the reproductive performance of all strains was evaluated using a completely randomized design with 5 replicates of 30 birds each. Females were artificially inseminated with the pooled semen of cockerels, and eggs were stored for incubation for 7 days. Data were analyzed using SAS procedures (SAS, 1996).

\section{RESULTS AND DISCUSSION}

Figures $1 \mathrm{~A}$ and $1 \mathrm{~B}$ show the absolute fertility and hatchability of all strains over all generations, respectively. The genetic trend of the selected strains was calculated using the deviation from control strain CCC as show in Figures 2A and 2B. The low fertility and hatchability in the first generation were due to treatment of the eggs against Mycoplasma. The 
decrease in hatchability observed in the $2^{\text {nd }}$ generation was due to egg transportation and the longer storage period, 20 days, when the stocks were transferred from Pirai-RJ to Concórdia-SC. In that generation, conditions for saving and storing eggs differed between selected and control strains, contributing to differences in fertility and hatchability. A decrease in hatchability was observed in the $4^{\text {th }}$ generation and had no apparent reason.
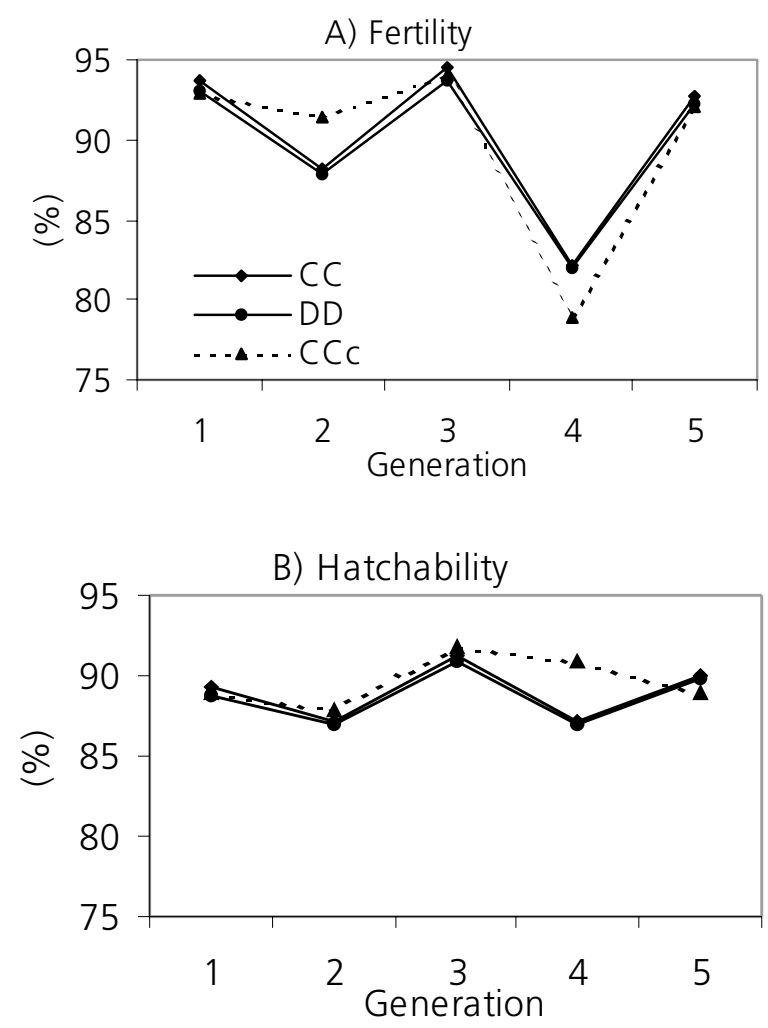

Figure 1 - Fertility $(A)$ and hatchability $(B)$ of selected (CC and DD) and control (CCC) strains over all generations.

The regression of the deviation between selected and control strains on generation number was not statically significant, suggesting that no genetic change occurred in fertility and hatchability of CC and DD after the selection had started. The high fertility (94.2\%) and hatchability $(92.6 \%)$ obtained in the last generation (Table 3) and the absence of significant differences between selected and control strains $(p>0.05)$ indicate that the selection practiced maintained the high initial performance.

Major genes affecting fertility and hatchability have been reported (Merat, 1990; Froman et al., 1992). The practiced selection for fertility and hatchability was based on the hypothesis of selection against low

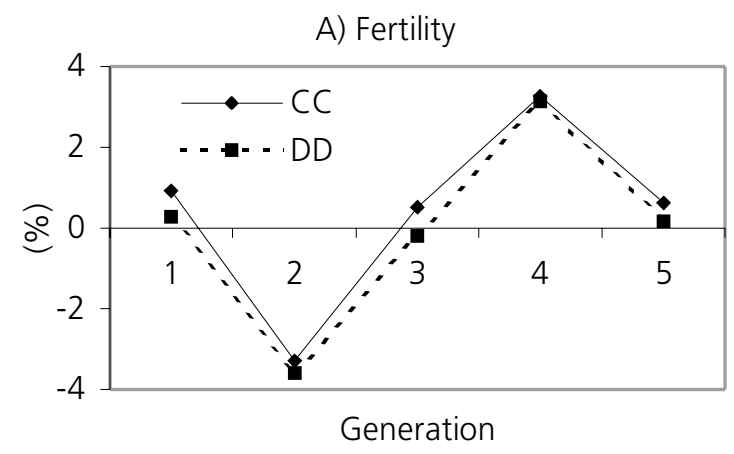

B) Hatchability

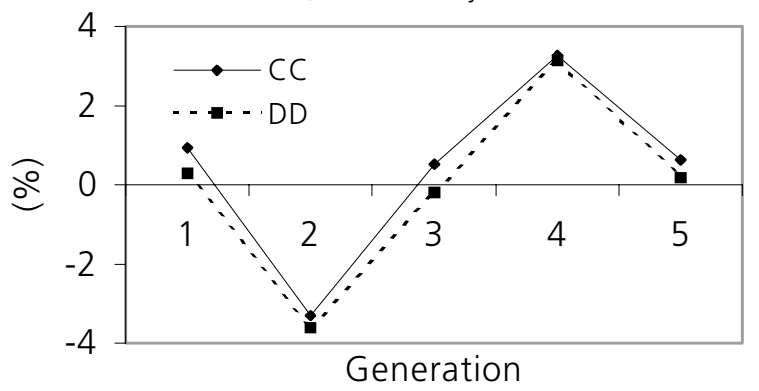

Figure 2 - Selected strain plotted as deviations from control strain to show genetic trends for fertility $(A)$ and hatchability (B).

frequency and deleterious recessive genes, and considering that heritabilities of fertility and hatchability are low and asymmetric. Furthermore, mean fertility and hatchability were very high with little scope for improvement. These considerations suggest that conventional selection indices would be relatively inefficient. Despite the initial problems due to the transfer of the stock, satisfactory means for both traits were maintained. These results demonstrate that the selection using independent culling levels was effective and confirm other published results (Gowe et al., 1993), suggesting that this method can make efficient use of limited selection intensity.

Inbred lines of laying hens show reduced reproductive performance (Ablanalp, 1990). This would be expected from segregation of undesirable genes at some loci. Additionally, selection may not alleviate the detrimental effects of rapid inbreeding (Nordskog \& Hardiman, 1980; Ibe et al., 1983), possibly because undesirable genes may become fixed. In inbred lines, hatchability is generally more affected than fertility.

Estimated inbreeding coefficients $\left(F_{r}\right)$ in the last generation for CC, DD and CCC were 1.81, 1.88 and 1.71 , respectively (Table 2 ). For $C C$ and $D D, F$ was underestimated because selection effects were not accounted for. In all strains, inbreeding increased about 


\begin{tabular}{|c|c|c|c|c|c|c|c|c|c|c|c|c|c|}
\hline \multirow[t]{2}{*}{ Generation } & \multicolumn{3}{|c|}{ CC } & \multicolumn{3}{|c|}{ DD } & \multicolumn{3}{|c|}{$\mathrm{CCc}$} & \multicolumn{2}{|c|}{ DIF (CC) } & \multicolumn{2}{|c|}{ DIF (DD) } \\
\hline & FERT & HATC & INB & FERT & HATC & INB & FERT & HATC & INB & FERT & HATC & FERT & HATC \\
\hline 1 & 93.75 & 89.20 & 0.175 & 93.10 & 88.76 & 0.170 & 92.82 & 88.90 & 0.175 & 0.93 & 0.30 & 0.28 & -0.14 \\
\hline 2 & 88.10 & 87.20 & 0.350 & 87.80 & 86.94 & 0.300 & 91.40 & 87.80 & 0.264 & -3.30 & -0.60 & -3.60 & -0.86 \\
\hline 3 & 94.50 & 91.20 & 0.401 & 93.78 & 90.88 & 0.470 & 93.98 & 91.75 & 0.317 & 0.52 & -0.55 & -0.20 & -0.87 \\
\hline 4 & 82.10 & 87.20 & 0.611 & 81.97 & 86.97 & 0.610 & 78.83 & 90.86 & 0.662 & 3.27 & -3.66 & 3.14 & -3.89 \\
\hline 5 & 92.76 & 90.05 & 0.274 & 92.31 & 89.76 & 0.330 & 92.13 & 88.97 & 0.305 & 0.63 & 1.08 & 0.18 & 0.79 \\
\hline Mean & 90.24 & 88.97 & 1.811 & 89.792 & 88.66 & 1.880 & 89.83 & 89.66 & 1.72 & 0.41 & -0.69 & -0.04 & -0.99 \\
\hline
\end{tabular}

$0.40 \%$ per generation. The regression of percentage inbreeding on generation number was positive and significant for all strains. Despite these increases in inbreeding, fertility and hatchability were not affected suggesting that any depressive effects of inbreeding might have been compensated by selection.

There are very few long-term, multiple-trait selection experiments reporting results of fertility, hatchability and inbreeding. Two of such studies have reported high reproductive performance after 35 years of selection with $39 \%$ inbreeding (Hutt, 1969), and after 29 or 30 years of selection with 21 to $36 \%$ inbreeding (Gowe et al., 1993). These results indicate that it is possible to maintain high reproductive performance in layer strains when inbreeding increases gradually.

In the $5^{\text {th }}$ generation, the frequency of dams with extremely low fertility and hatchability $(<10 \%)$ was greater in the control than in the selected strains. This reduction for both traits is consistent with the hypothesis of segregation of deleterious recessive genes in low frequency and illustrates the results of selecting against families with low fertility and hatchability for a few generations. Gowe et al. (1993) obtained similar results by selecting on pedigree performance.

Poultry breeding companies usually do not publish inbreeding rates or fertility and hatchability of their strains. However, their continued success depends on high levels of performance in these traits. Ameli et al. (1991) analyzed data from Lohmann Tierzucht GmbH's commercial breeding program and reported that the practiced selection maintained fertility and hatchability even with an increase in inbreeding of $0.6 \%$ per generation. In the Kimber Poultry Farm program, it is used an index of 18 traits including fertility and hatchability, and fertility and hatchability were maintained for 13 generations with no significant genetic trend (Kashyap et al., 1981). However, the genetic response for egg laying rate was only $25 \%$ of the response obtained by Gowe et al. (1993).

\begin{tabular}{cccccc}
\hline $\begin{array}{l}\text { Table } 3 \text { - Means and standard errors (s.e.) for fertility and } \\
\text { hatchability in the last generation test. }\end{array}$ \\
\begin{tabular}{cccccc} 
Strain & \multicolumn{2}{c}{ Fertility } & & \multicolumn{2}{c}{ Hatchability } \\
\cline { 2 - 3 } \cline { 5 - 6 } & Mean & s.e. & & Mean & s.e. \\
CC & 93.80 & 1.54 & & 93.20 & 1.83 \\
DD & 93.80 & 2.27 & & 91.60 & 2.68 \\
CCC & 94.90 & 2.82 & & 93.20 & 2.19 \\
Mean & 94.20 & 2.15 & & 92.70 & 2.17 \\
\hline
\end{tabular}
\end{tabular}

\section{CONCLUSION}

Selection for reproductive traits through independent culling levels, instead of including them in a selection index, provides higher selection intensity for the other traits in layer strains. Independent culling levels allow to alleviate the effects of inbreeding on fertility and hatchability and to maintain both traits in satisfactory levels in breeding programs, even if the inbreeding coefficients increase gradually.

\section{REFERENCES}

Abplanalp H. Inbreeding. In: Crawford RD. Poultry breeding and genetics. Amsterdan:Elsevier Science Publishers; 1990. p.955-984.

Ameli H, Flock DK, Glodek P. Cumulative inbreeding in commercial White leghorn lines under long-term reciprocal recurrent selection. British Poultry Science 1991; 32:439-449.

Fairfull RW, Gowe RS. Egg Production in Chickens. In: Crawford RD. Poultry breeding and genetics. Amsterdan: Elsevier Science Publishers; 1990. p.705-759.

Froman DP, Kirb JD, Al-Aghbari AM. Analysis of the combined effect of the spermatozoal degeneration allele $(S d)$ and homozygosity of the rose comb allele ( $R$ ) on duration of fertility of roosters (Gallus domesticus). Poultry Science 1992; 71:1939-1942.

Gowe RS, Fairfull, RW. The direct response for long-term selection for multiple traits in egg stocks and changes in genetic parameters with selection. In: Hill WG, Manson JH, Hewitt D. Poultry genetics and breeding. Edinburg: Longman; 1985. p.125-146.

Gowe RS, Fairfull RW, McMillan I, Schmidt GS. A strategy for maintaining high fertility and hatchability in a multiple-trait egg 
stock selection program. Poultry Science 1993; 72:1433-1448.

Hutt FB. Genetic aspects of fertility and hatchability in the fowl. In: Carter TC, Freeman, BM. The fertility and hatchability of hen's egg. Edinburg: Oliver and Boyd; 1969. p.49-56.

Ibe SN, Rutledge JJ, McGibbon W.H. Inbreeding effects on traits with and without selection for part records rate on lay in chickens. Poultry Science 1983; 62:1543-1547.

Kashyap TS, Dickerson GE, Bennett GL. Effectiveness of progeny test index selection for field performance of strain-cross layers. I. Estimated responses. Poultry Science 1981; 60:1-21.

Merat P. Pleiotropic and associated effects of major genes. Egg production in chickens. In: Crawford RD. Poultry breeding and genetics. Amsterdan: Elsevier Science Publishers; 1990. p.429-467.

Nordskog AW, Hardiman J. Inbreeding depression and natural selection as factors limiting progress from selection in poultry. In: Selection experiments in laboratory and domestic animals. Slough: England; 1980. p.91-99, 1980.

SAS Statistical Analysis Systems User's Guide: Stat. Version 6. 1996 


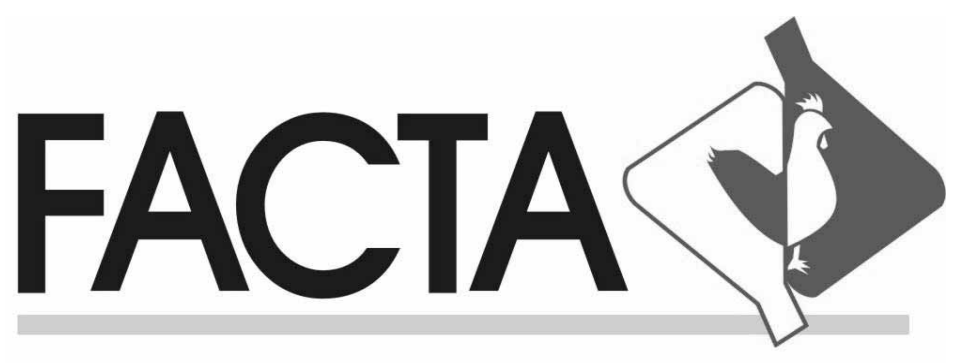

Fundação APINCO de Ciência e Tecnologia Avícolas

\section{CONFERÊNCIA APINCO'2006}

Data: 03, 04 e 05 maio de 2006

Local: Mendes Convention Center

Santos - São Paulo - Brasil

Informações: www.facta.org.br 